\title{
Entrepreneurial ecosystem governance: a principal investigator-centered governance framework
}

\author{
James A. Cunningham • Matthias Menter • \\ Katharine Wirsching
}

\begin{abstract}
Research on entrepreneurial ecosystems has largely taken a macro-perspective to better conceptualize and map the determinants and evolution of entrepreneurial ecosystems, yet has neglected the micro-level interactions of various entrepreneurial ecosystem actors. Recent criticisms of entrepreneurial ecosystems have centered on the lack of explicit case and effect relationships, attribution, units of analysis, the different use of network definitions as well as the static nature of existing frameworks. The purpose of our paper is to present a micro level principal investigator (PI)-centered governance framework that addresses these posited criticisms and in doing so identifies the value creation indicators (benefits), PI capabilities, the problem categories (costs), and solving mechanisms that PIs can use to govern effectively and efficiently large-scale publicly funded research programs. In leading such research programs, PIs interact with different actors within entrepreneurial ecosystems and manage governance issues,
\end{abstract}

\footnotetext{
J. A. Cunningham $(\bowtie)$

Newcastle Business School, Northumbria University, Newcastle upon Tyne, UK

e-mail: james.cunningham@northumbria.ac.uk

M. Menter $\cdot$ K. Wirsching

Faculty of Business and Economics, University of Augsburg,

Augsburg, Germany

M. Menter

e-mail: matthias.menter@wiwi.uni-augsburg.de

K. Wirsching

e-mail: katharine.wirsching@wiwi.uni-augsburg.de
}

conflicts, and tensions effectively at the micro level to deliver the anticipated benefits and costs for each actor. Our framework provides the basis for future empirical research on entrepreneurial ecosystem as we have attributed cause and effect at an individual actor level and conceptualized the governance challenges at a micro rather than at the macro level that overcomes the static nature of previous frameworks.

Keywords Entrepreneurial ecosystems · Principal investigators · Governance dilemmas · Governance mechanisms $\cdot$ Principal-agent theory Problem categories $\cdot$ Capabilities

JEL classification $\mathrm{L} 26 \cdot \mathrm{O} 31 \cdot \mathrm{O} 32$

\section{Introduction}

The literature on entrepreneurial ecosystems has identified a range of actors and supporting institutions that encourage and support formally and informally entrepreneurial activities and their diffusion (Acs et al. 2014; Colombo et al. 2015). Research on entrepreneurial ecosystems to date has largely taken a macro perspective and has focused on such issues as attributes (Spigel 2015), environmental factors (Suresh and Ramraj 2012), evolutionary trajectories (Mack and Mayer 2016), global innovation networks (Malecki 2011), high growth firms (Mason and Brown 2014), environmental sustainability (Cohen 2006), clusters, co-creation, and appropriability (Pitelis 2012). Acs et al. (2014: 479) 
define entrepreneurial ecosystems as the "dynamic, institutionally embedded interaction between entrepreneurial attitudes, ability, and aspirations, by individuals, which drives the allocation of resources through the creation and operation of new ventures". Such interactions between various institutions and actors within entrepreneurial ecosystems give rise to governance challenges including resource distribution and dealing with conflicts related to the allocation of costs and benefits. There is a dearth of research focusing on these issues at a micro level, which is the focus of this paper.

Spigel (2015) argues that research on entrepreneurial ecosystems is under-theorized and -developed. To date, scholars have conceptualized different ways of how entrepreneurial ecosystems evolve and develop (see Mason and Brown 2014; Mack and Mayer 2016; Spigel 2015, Stam 2015; Pitelis 2012). Such research has taken a macro perspective to better conceptualize and map the determinants and evolution of entrepreneurial ecosystems. Taking account of previous research and criticisms, we adopt a different approach in conceptualizing entrepreneurial ecosystems by developing a micro level conceptual framework centered around the principal investigator (PI). The PI is an influential entrepreneurial ecosystem actor, whose actions and behaviors shape and influence the management of governance within the entrepreneurial ecosystem that supports the creation of new ventures with disruptive knowledge and provides resources and capabilities for existing firms to compete more effectively. Publicly funded PIs have to deliver on their scientific research programs and allocate resources efficiently and effectively as well as deal with multiple governance systems, actors, and relationships based on incomplete contracts. The nature of their role means they interact, engage, and boundary span with other entrepreneurial ecosystem actors (see Boardman and Ponomariov 2014; Casati and Genet 2014, Kidwell 2013, 2014; Menter 2016; O'Kane et al. 2015). Increasingly PIs are being mandated by publicly funded research programs to participate in technology transfer and entrepreneurial activities in collaboration with other entrepreneurial ecosystem actors such as funding agencies, venture capitalists, banks, entrepreneurs, high growth SMEs, MNCs, etc. Some of these nonscientific outcomes are uncertain and concerning publicly funded research, outcomes are contractually based on incomplete contracts adding further complexity to their governance.
To manage and deal with all the governance issues associated with large-scale publicly funded research within entrepreneurial ecosystems (Hagendijk and Irwin 2006), PIs need to possess certain capabilities to navigate, arbitrate, and shape the governance mechanisms of different actors and supporting institutions as well as fulfilling their PI roles and responsibilities successfully (see Mangematin et al. 2014). To contribute to the overall value creation within an entrepreneurial ecosystem, PIs need to have the capabilities to allocate resources, costs, and benefits among entrepreneurial ecosystem actors on the basis of incomplete contracts. PIs have an influential role in the governance of largescale publicly funded research through their boundary spanning activities with entrepreneurial ecosystem actors, thus influence appropriate and effective governance mechanisms within entrepreneurial ecosystems aimed at creating new and disruptive knowledge for new ventures and existing firms.

To date, research on entrepreneurial ecosystems and corresponding governance issues has mainly been driven by studies of entrepreneurship and new venture creation in the private sector (see Acs et al. 2017). Existing ecosystem frameworks have taken macro perspectives and have neglected the dynamic role of specific ecosystem actors. Our paper adds to the under-developed entrepreneurial ecosystem literature as argued by Spigel (2015) by focusing on the micro level principal investigator governance issues of entrepreneurial ecosystem that contribute to "productive entrepreneurship" (see Stam 2015: 1764). The contribution of this paper is twofold. First, while previous entrepreneurial ecosystems frameworks focused on the macro level, our framework is at the micro level and attempts to address the need for a more operational level understanding of entrepreneurial ecosystem as highlighted by Stam and Bosma (2015). Our micro level PI-centered governance framework specifically identifies the value creation (benefits), PI capabilities, the problem categories (costs), and solving mechanisms that PIs can use to govern effectively and efficiently large-scale publicly funded research programs based on imperfect contracts. Second, through our framework, we directly address criticisms of entrepreneurial ecosystem attribution of cause and effect, unit of analysis, use of different network definition, and the static nature of entrepreneurial ecosystem frameworks (see Alvedalen and Boschma 2017; Stam and Spigel 2016). By taking a micro level perspective, our framework outlines the principal-agent 
relationships that PIs have with other ecosystem actors as well as identifies the potential types of problem categories that can emerge as they seek to contribute economic and non-economic value to entrepreneurial ecosystems. We outline and discuss the primary capabilities that PIs need in order to participate and contribute to productive entrepreneurship in entrepreneurial ecosystems for ecosystem actors as well as the allocation of costs and benefits. Based on our micro level conceptual framework, we suggest future avenues of research on how PIs deal effectively with conflicting governance mechanisms that constrain their actions, value creation activities, and the allocation of costs and benefits to relevant entrepreneurial ecosystem actors.

The remainder of the paper is structured as follows: Section 2 presents entrepreneurial ecosystems, the PI role, burdens, and challenges for PIs in leading largescale publicly funded research projects as well as responsibilities of PIs as entrepreneurial actors. Section 3 considers some primary capabilities of PIs that enable them to navigate, arbitrate, and shape different governance mechanisms, tackle potential governance dilemmas, and contribute to the performance of entrepreneurial ecosystems. Section 4 discusses the governance of entrepreneurial ecosystems and specifically boundaries of entrepreneurial ecosystems, incomplete contracts and resulting governance problems, multiple principal agent relationships, and the costs and benefits of governance. Section 5 outlines our PI-centered entrepreneurial ecosystem governance framework. A final section provides some concluding remarks and discusses future research avenues.

\section{Entrepreneurial ecosystems and the role of principal investigators}

\subsection{Entrepreneurial ecosystems}

Entrepreneurship theory has highlighted exploitation activities of entrepreneurs, yet has neglected the actual environment of entrepreneurs opening up entrepreneurial opportunities (Szerb et al. 2015). As the adequate entrepreneurial context constitutes the basis for any entrepreneurial activity, i.e., due to the high contextdependency of entrepreneurial actions, scholars introduced the concept of entrepreneurial ecosystems as a synonym for relevant factors and resources necessary to create economic knowledge through entrepreneurial engagement (Acs et al. 2014). The perspectives of industrial districts (Krugman 1991; Markusen 1996), clusters (Porter 1998), and innovation systems (Freeman 1987; Lundvall 2010) have taken firms as the focal point. However, Stam (2015: 1761) emphasizes that "the entrepreneur, rather than the enterprise, is the focal point [of entrepreneurial ecosystems]. The entrepreneurial ecosystem approach thus begins with the entrepreneurial individual instead of the company, but also emphasizes the role of the entrepreneurship context".

For entrepreneurs, access to knowledge is critical and shared through social networks (formal and informal). These entrepreneurs are essential for maintaining and growing the entrepreneurial system with government support (Stam and Spigel 2016). Creating and enabling such entrepreneurial ecosystems requires strategies as using policy to favor incumbents, engaging with entrepreneurs, creating an ecosystem map for further policy strategies, and build on early successes (see Auerswald 2015). Within European cities, Audretsch and Belitski (2016) find that culture, infrastructure, formal institutions, and internet access are important factors in enhancing entrepreneurial ecosystems and activities.

Entrepreneurial ecosystems are evolutionary with culture, history, and institutional settings shaping them over time (Mack and Mayer 2016). There are different pathways to creating entrepreneurial ecosystems and certain actor roles are more prominent depending on the context (Kshetri 2014). Mason and Brown (2014: 13) argue that entrepreneurial ecosystems emerge in "places that already have an established and highly regarded knowledge base which employs significant numbers of scientists and engineers" and that there is technology disruption that creates new opportunities.

Within these ecosystems, the entrepreneur interacts with universities, which produce and disseminate new and potentially disruptive knowledge, and new ventures and incumbent firms, which transform and apply that knowledge, hence constitute the nexus between science and business. Beyond firms and research organizations, capital providers as well as governments and public bodies play a crucial role within entrepreneurial ecosystems as they influence and shape the manner in which entrepreneurs direct their abilities (Sölvell 2015). Vibrant ecosystems enable the efficient flow of knowledge and ideas between various entities, thus form the basis for economic and non-economic value creation that enables "productive entrepreneurship." The outcomes of entrepreneurial systems can thereby vary among stakeholders (Stangler and Bell-Masterson 2015). 
Within the literature, different frameworks and models have emerged of entrepreneurial ecosystems. Isenberg (2011) posits six domains and twelve components of entrepreneurial ecosystems. Whereas Spigel (2015), using Canadian case studies, identifies ten cultural, social, and material attributes of entrepreneurial ecosystems that support entrepreneurs. Such models take a macro perspective, hence do not address the attribution of outcomes, costs, and benefits which is one of the main criticisms of entrepreneurial ecosystems (Stam 2015; Stam and Bosma 2015).

There have been critical perspectives emerging about entrepreneurial ecosystems such as its tautological nature, the missing clarity about cause and effects in relation to specific factors, units of analysis and attribution of contributory factors for economic outcomes (Stam and Spigel 2016). Alvedalen and Boschma (2017) note several deficits of existing frameworks including a lack of explicit cause and effect relationships, the use of different network definitions, the place-/ cluster-based nature of empirical studies to date as well as the static nature of existing frameworks that do not account for the evolution over time. Furthermore, Stam and Bosma (2015) emphasize that the operational level of entrepreneurial ecosystems has yet to be addressed adequately in the literature. Given the challenges of attributing costs and benefits to entrepreneurial ecosystems, Stangler and Bell-Masterson (2015) suggest density, fluidity, connectivity, and diversity as vibrancy indicators.

Existing entrepreneurial ecosystem models have identified the importance of skilled labor and the role of university and publicly funded research. Our focus is at the individual level and extends the entrepreneur focus of Stam (2015). Within publicly funded largescale research projects, the PI takes over the described entrepreneurial role with their funded project forming the nucleus around an imperfect contract. Kuratko and Menter (2017: 45) consequently characterize PIs as entrepreneurial ecosystem actors who "create conducive environment themselves as well as with the help of political programs and consequently build the breeding ground for further entrepreneurial action". The PI engages in both managing different stakeholders for public science, but also in designing, resourcing, and delivering large-scale publicly funded projects, arbitrating and attempting to distribute the costs and returns for relevant entrepreneurial ecosystem actors. The emerging literature on PIs describes them as scientific entrepreneurs who shape new paradigms, reshape the boundaries of organizations, and span boundaries between the public and private sector (Casati and Genet 2014; Mangematin et al. 2014), thus strive for mutual beneficial outcomes that can enhance economic and non-economic value around disruptive knowledge (McAdam et al. 2012).

In an ideal entrepreneurial ecosystem, public research outputs would complement industry inputs and result in efficient processes and satisfactory outcomes that underpin productive entrepreneurship. The reality looks different, as basic research, e.g., from universities, does not directly diffuse in marketable product or process innovations, as suggested by the linear model of innovation (Leyden and Menter 2017). Academia and industry often pursue divergent or even conflicting targets and are simultaneously affected by their regional endowment and corresponding governance mechanisms imposed by government (Lehmann and Menter 2016): whereas universities and research institutions might be interested in the disclosure of new knowledge through publications, industry might target the protection and commercialization of intellectual property. PIs have to align those opposing objectives, outweigh financial and scientific interests, and strive for efficient processes despite contrary objectives of the individual actors (Nambisan and Baron 2013). In dealing with such conflicts and constraints, this then creates an array of managerial challenges for PIs particularly at the project level (see Cunningham et al. 2015a).

\subsection{The PI role and activities in complex multi-stakeholder public research projects}

Scientists in the principal investigator role are part of the entrepreneurial ecosystem. As the changing nature of individual academic roles (Slaughter and Leslie 1997) and the evolution of entrepreneurial university (Etzkowitz 1983, Guerrero et al. 2015) are blurring the boundaries between science and business; the role-identity of scientists is being modified (Jain et al. 2009; Lam 2010). This paradigm shift results in the emergence of a new identity in the scientific community. Scientists are awarded research funding for the detailed interpretations and project plans that are disruptive and original in nature that can contribute to productive entrepreneurship for ecosystem actors. In the PI role, scientists take on management roles in the governance, implementation, and realization of large-scale publicly funded research programs. Thus, in formulating and delivering on public research programs, PIs are becoming influential agents of economic and social change. Mangematin et al. (2014: 2) summarize the PI role 
and relevance as follows: "They play a specific role in the new governance of research as they are the ones who design research projects and manage their implementation. $[\ldots]$ These new roles also involve coordinating with multiple organizations, including industry partners, and generally making the job of the principal investigator more important and policy relevant".

There are growing empirical studies of scientists in the PI role. For a scientist, becoming a PI is a career enhancing and offers a real opportunity to shape activities with respect to science and markets as well as research productivity (Feeney and Welch 2014). The PI role provides scientists with status within the academic community and an additional allocation of resources that has the potential to contribute to economic and non-economic value of entrepreneurial ecosystems (see O'Kane et al. 2015). It provides opportunities for scientists to work and engage with other scientists in academic, public research, and industrial organizational settings and to build their own research teams and networks. Taking on the PI role for a scientist means that they are taking on additional responsibilities and roles that are necessary to provide the basis of disruptive knowledge that contributes to productive entrepreneurship. It also requires PIs to remove constraints that prevent entrepreneurship and innovation. In achieving this, Cunningham et al. (2016) identified ten types of responsibilities and roles of PIs who simultaneously act as scientists, research strategists, project managers, team leaders, knowledge brokers, administrators, stakeholder managers, project promoters, resource managers, supervisors, and mentors, indicating the complexity of PIs' tasks. In essence, the PI, as Boehm and Hogan (2014) argue, is akin to an entrepreneur and needs to be a "jack of all trades" to manage complex multi-stakeholder relationships. Moreover, they suggest that PIs are even better placed to manage the gap between industry and academic environments. PIs are knowledge brokers who create value by bridging structural holes and building trust between the lab and industry through four distinct activities: extrapolation, seeking, aligning, and anticipating (Kidwell 2013).

PIs are highly strategic in choosing their institutions in order to progress their research agenda and they actively seek environments that support and value their research activities and ambitions (Kidwell 2014). They seek out suitable entrepreneurial contexts or places that have vibrant entrepreneurial ecosystems (Auerswald 2015). PIs being a "jack of all trades" means they can create knowledge and novelty that new ventures can use and exploit, manage governance issues and relationships effectively, contribute to productive entrepreneurship, arbitrate the costs and benefits to each shareholder, and contribute to the economic and non-economic value creation of entrepreneurial ecosystems. PIs challenge systems and processes (Kidwell 2014) and are nonconformists (O'Kane et al. 2015) who can subvert governance systems and rules.

Micro institutional conditions and supports do influence the PIs' academic entrepreneurship decisionmaking and high levels of trust between all stakeholders are critical and essential (Organ and Cunningham 2014). PIs can also make the deliberate decision to leave a university setting to set up their own firm so that they can enhance their sphere of influence and use it as a mechanism to shape their research agenda and the market opportunity (Baglieri and Lorenzoni 2014). Based on a study of five PIs, Baglieri and Lorenzoni (2014) show how PIs positioned themselves closer to the market that enabled them to provide roadmaps and identify customer needs as well as actively participate in the value creation process. Moreover, Casati and Genet (2014) argue that PIs are scientific entrepreneurs that engage in envisioning, value creation, and resourcing actions. They further argue that PIs shape their environment and have the entrepreneurial characteristic to engage in science and the external environment. Furthermore, PIs with proactive postures challenge existing technology trajectories and shape new ones (O'Kane et al. 2015). The actions and approaches of scientists in the PI role for publicly funded research thereby contribute to the vibrancy and development of entrepreneurial ecosystems.

\subsection{Challenges and burdens for PIs of publicly funded large-scale research projects}

For scientists, becoming a PI places additional responsibilities with respect to governance, leadership, and management of large-scale public science projects on them. With respect to the governance of publicly funded scientific programs, PIs are responsible for all scientific and financial aspects of their projects (see Cunningham et al. 2016). Their day-to-day responsibilities include research leadership and management of the project, dealing with internal and external stakeholders (TTOs, entrepreneurs, funders etc.) as well as supervising and mentoring researchers to ensure that the overall project deliverables are met. Given the additional responsibilities concerning leadership and management, 
Cunningham et al. (2016: 71) note that "all of this is to be achieved within as many as three layers of control mechanisms, including their own institution, the public funding agency and the project-specific controls".

The managerial activities and burdens that scientists in the PI role face can be extensive. Cunningham et al. (2015a) found that PIs experienced three main categories of managerial challenges - project management, project adaptability, and project network management - and they used a variety of approaches to deal with these challenges. They found that PIs are more deeply involved in project operational management and intensively involved in science brokering activities and that the managerial role has a low status among PIs. In their study of a sample of US research centers, Boardman and Ponomariov (2014) find that PI management know-how is not equal and this raises interesting questions about the impact on research productivity. Furthermore, Boehm and Hogan (2014) argue the need for PIs to have a broader commercial understanding and awareness that supports boundary spanning activities, particularly inter-organizational ones. In their study on entrepreneurial performance of PIs and company culture, Del Giudice et al. (2016) emphasize that national culture can influence PIs' orientation toward entrepreneurship.

In discharging their project responsibilities PIs experience barriers or what Cunningham et al. (2014) describe as inhibiting factors that can hinder the realization of their scientific vision and ambition as well as outcomes for other ecosystem actors. They identified three levels of inhibitors: political and environmental, institutional, and project inhibitors. In particular, the institutional inhibitors centered on dedicated technology transfer support, tailored support for the PI role, and human capital support. These impeded the operational management for PIs and highlighted core tensions of the role between research management and leadership.

\subsection{Responsibilities of PIs as entrepreneurial actors}

To survive in a shifting public research environment that increasingly rewards academic entrepreneurship, knowledge translation, and economic impact, PIs are adopting the role of scientific entrepreneurs. Consistent with this view, many of the tasks now undertaken by PIs have expanded beyond scientific avenues and resemble those of traditional entrepreneurs. For example, there is increasing acknowledgement that PIs contribute to industry growth (Audretsch and Stephan 1996; Zucker et al. 2002), acquire capital and resources (Forti et al. 2013; Kidwell 2013), and act as inventors and market shapers (Baglieri and Lorenzoni 2014; Casati and Genet 2014; Murray 2004) as well as boundary spanning agents who connect scientific inquiry, innovation, and industry (Boehm and Hogan 2014; Gittelman and Kogut 2003). Added to this, a number of scholars have emphasized the research management duties associated with the PI role (Adler et al. 2009; Boardman and Ponomariov 2014), while Etzkowitz (2003) refers to research groups that are led by PIs as "quasi-firms." Moreover, the PI role involves significant coordination among entrepreneurial ecosystem actors. The expansion of the role and activities beyond traditional scientific leadership has created a new tension for scientists, particularly around governance as Mangematin et al. (2014: 2) describe: "In the new governance of science and universities, principal investigators have increased responsibility as scientific fiduciaries. The legal and the informal responsibilities entailed in the financial management of research pose new administrative challenges for the principal investigator, requiring them to measure carefully the balance of research management and research leadership in their approach to their principal investigator mission. Can they, simultaneously, be entrepreneurs and administrators?"

In summary, publicly funded PIs are entrepreneurial actors within entrepreneurial ecosystems and in the creation of disruptive knowledge and productive entrepreneurship. PIs can contribute to economic and noneconomic value through fulfilling their PI role and the associated responsibilities. Hence, PIs are involved in engaging and interacting with a wide range of entrepreneurial ecosystem actors and they have to deal with complex governance issues based on an imperfect contract. The PI role, while it gives scientists a status within their academic community, also imposes an entrepreneurial mandate as well as a governance mandate that is required to contribute to productive entrepreneurship.

\section{Primary capabilities of PIs in contributing effectively to governance of entrepreneurial ecosystems}

To contribute effectively to the economic growth of entrepreneurial ecosystems and productive entrepreneurship, PIs need to possess capabilities that bridge 
the expectations of different actors. Sölvell (2015: 89f.) describes potential conflicts within entrepreneurial ecosystems as follows: "Small firms who believe they have something new exciting to offer have a hard time meeting with the right people at a large firm. Large firms searching for a new supplier are more likely to look for an established international supplier than go searching among innovative SMEs located right under their nose. Policymakers often have only vague ideas about what business really needs. Researchers are more interested in academic publishing than commercializing their new findings. [...] Entrepreneurs find it difficult to persuade banks to invest in new innovative businesses". PIs need to be a "jack of all trades" (see Boehm and Hogan 2014), having primary capabilities that enable them to address the specific needs of different actors and contribute to the actors' value creation processes through economic and non-economic ends. To attain this, PIs proactively drive innovation, primarily through knowledge and create value by simultaneously interacting with a multitude of actors (O'Kane 2016). It is the PIs' competency and experience that contributes to the efficient and effective value creation processes. Taking the growing body of empirical studies of PIs, we identify some of the primary capabilities that PIs need to possess in order to effectively shape governance relationships that ultimately enhance the overall value of an entrepreneurial ecosystem.

\subsection{Researcher and scientific excellence}

Being an excellent researcher is a central capability that funded PIs need to have in order to be successful in leading large-scale publicly funded projects that involve academic and industry partnerships (Cunningham et al. 2015b). This is evaluated through peer review processes, where the project ideas as well as the scientific track record of the PI and associated research teams and partners are evaluated and assessed as well as the potential impacts beyond scientific ones. In their study of French PIs, Casati and Genet (2014: 16) term the demonstration of scientific excellence as "producing science" meaning that "PIs 'produce' science, technologies and innovation and the outputs of their activity are measurable". Some PIs seek public funding to pursue existing scientific trajectories and build on the scientific excellence that they have created while others open new scientific trajectories (see O'Kane et al. 2015). PIs' scientific work is focused around problem-based activities, providing some solutions and answers for policymakers (Mangematin et al. 2014).

\subsection{Research leadership}

Becoming a PI places additional research leadership and managerial responsibilities on scientists. PIs need to have a capability in both to ensure that they comply with different governance and control mechanisms of various entrepreneurial ecosystem actors such as funding agencies, their own institution and any industry or enterprise partners. Research leadership capabilities relate to ensuring that the funded project delivers the desired scientific outcomes, whereby the PIs' capabilities are leading and coordinating scientific outcomes typically across a number of academic and now increasingly industry partners (see Cunningham et al. 2015a), based on imperfect contracts. The role of the PI is to provide academic leadership. The foundation of this research leadership is achieved through their scientific excellence and track record.

\subsection{Managerial responsiveness}

Cunningham et al. (2015a, 2015b) posit that the PI role has become managerial in nature in terms of the core functions of management (planning, leading, organizing, and controlling). PIs not alone become academic leaders but are viewed as institution leaders. PIs need to have research managerial capabilities to deal effectively with a variety of activities related to finance, human resources, legal, intellectual property (IP), etc. to successfully deliver publicly funded research projects. Part of their managerial responsibility is to ensure that all members of the funded project are compliant with research ethics and professional body requirements. The managerial tasks and challenges for PIs focus on project management, project adaptability, and network challenges (see Cunningham et al. 2015a). Based on their study of Irish PIs, Cunningham et al. (2014) found that the balance for PIs is more on research management and less on research leadership. PIs are in essence CEOs of temporary organizations within their own institution (see Mangematin et al. 2014). Managerial responsiveness thus means that PIs have to deal with core managerial tensions and changing conditions and objectives: entrepreneurial versus scientific outputs; balancing existing workloads versus applying for new funding opportunities; IP protection versus IP exploitation; 
project sustainability versus continual loss of talents and experiences; research management versus research leadership; managing power of collaboration partners. With respect to entrepreneurial ecosystems, this capability ensures that allocated resources - as well as associated costs - are deployed, managed, and utilized in a manner that can maximize economic and non-economic value creation that meets the demands and anticipated benefits of different actors within governance systems.

\subsection{Resource acquisition}

One of the core capabilities of a PI is to secure both hard and soft resources to realize their scientific missions or as Kidwell (2014: 34) describes "they must steer their careers in ways that position them to accomplish their research agenda with appropriate resources". The hard resources typically center on equipment and lab space to conduct their research. Soft resource support is usually focused on institutional support for the PI role and associated activities. This means in effect that PIs have support from various functions within their institutions to effectively and efficiently deliver the publicly funded programs and to be able to simultaneously engage with different actors within an entrepreneurial ecosystem. Being an effective resource acquirer means that the PI has the necessary threshold resources (hard and soft) in order to deliver against stated objectives for publicly funded projects. This capability also supports the PI to realize more autonomy and research space to conduct their research and related activities. It also means that the PI has the necessary resources that can have the potential to contribute to value creation for other entrepreneurial ecosystem actors.

\subsection{Boundary spanning and relationship building}

Empirical studies to date on PIs have consistently highlighted the need for PIs to be capable with respect to building relationships internally and externally to their own institutions with multiple partners and have the ability to boundary span. Specifically, Boehm and Hogan (2014) highlight the need for PIs to build sustainable and effective inter-organizational relationships and to develop good personal relationships between research and industry partners. Casati and Genet (2014) found that PIs were involved in brokering science where they were transferring knowledge and expertise across domains and organizational settings as well as forming new networks. PIs need to have bridging capabilities between science and industry. As part of their boundary spanning activities and capabilities, PIs are open to collaborating with a wide variety of partners that help them to realize their scientific mission (Kidwell 2014; O'Kane et al. 2015). Such boundary spanning activities can enhance existing value creation or create new streams of economic and non-economic value for individual entrepreneurial ecosystem actors. This capability also contributes to good governance and relationships that are necessary for the functioning of entrepreneurial ecosystems.

\subsection{Envisioning, strategizing, and value creation}

Envisioning, strategizing, and value creation constitute three complementary capabilities that PIs need to possess. First, PIs are visionaries as they have a capability to have a clear vision of their scientific mission over the long term. Being visionary means that they appropriate resources and engage with different stakeholders in order to realize this scientific mission (Kidwell 2014). Casati and Genet (2014: 16) describe this envisioning as a dimension that "represents PIs' medium and long terms scientific vision and perspectives, and includes how they frame their overall scientific ambition as series of projects which match the requirements of public authorities". Strategizing is about how to realize their scientific vision and mission. O'Kane et al. (2015) find that PIs strategize constantly with some PIs being more strategic and selective in relation to competing for public funding. This requires PIs to balance short-term goals and operational demands against realizing the longerterm scientific vision and mission. Moreover, in their strategizing, PIs are creating alignment and synergies between their research, its application and the market place (see Cunningham et al. 2016). Value creation and capture is finally realized by PIs being able to link and exploit synergies between academic and user domains.

\section{The governance of entrepreneurial ecosystems}

Due to the inherent structure of entrepreneurial ecosystems and the fact that ecosystems are not formalized institutions or organizations but rather an informal plexus of relations between individuals, institutions, and organizations, often based on regional proximity, it seems to be impossible to develop a theory-based holistic framework 
for the governance of entrepreneurial ecosystems. Similar to clusters, entrepreneurial ecosystems are characterized by relational governance mechanisms and a lack of hierarchical structures as well as clear expressions of expectances, responsibilities, and objectives (Spigel 2015). Stam (2015) argues that entrepreneurial ecosystems are not comparable to classical market (failure) situations and consequently the classical "governance modes," namely the both extremes "market" and "hierarchy," are not sufficient in a discussion of mechanisms minimizing costs. Rather, the opportunity of creating a higher overall value justifies the important role that entrepreneurial ecosystems play in the welfare of regions and countries (Acs et al. 2014). Measuring the value created by an entrepreneurial ecosystem is only possible if firstly the boundaries of the ecosystem are defined and subsequently costs and benefits within the ecosystem but also arising conflicts between actors inside and spatially proximate, indirectly affected actors outside the ecosystem are identified and taken into account. The subsequent discussion of problems and solving mechanisms and multiple principalagent relationships demonstrates whether and in what manner PIs can add value by managing the governance of entrepreneurial ecosystems.

\subsection{The boundaries of the entrepreneurial ecosystem} as a nexus of incomplete contracts and resulting governance problems

In order to be able to explain and quantify the added value created by the entrepreneurial ecosystem, the definition of the boundaries of the ecosystem is an essential requirement. Stam and Spigel (2016) define entrepreneurial ecosystems "as a set of interdependent actors and factors coordinated in such a way that they enable productive entrepreneurship within a particular territory". Even though entrepreneurial ecosystems are not clearly delimited organizational constructs, they show the same properties, underlying conditions and problems like other organizations. As markets are imperfect, especially not frictionless and characterized by missing market transparency as well as irrational behavior of the participants, the extent of transaction costs dominates the composition of relationships between the different market players. Depending on the specification of transactions and products, contracts that can be onetime or repeating are concluded. Consequently, transaction costs, especially search and information as well as bargaining and enforcement costs, determine the boundaries of organizations. These universal implications from transaction cost theory (for a broader discussion see Coase 1937; Williamson 1985, 1989) hold for entrepreneurial ecosystems that can consequently be considered as a nexus of contracts (Jensen and Meckling 1976). Due to the fact that these contracts cannot specify every imaginable situation and resulting decision or action alternative, they can be described as incomplete by nature. Consequently, implicit and explicit, but still incomplete, multiple contracts exist between distinct entrepreneurial ecosystem actors.

As entrepreneurial ecosystems generate complex and multifarious outputs and with reference to the assumption that knowledge spillovers arise from these ecosystems (Acs et al. 2009), externalities can lead to undesired behaviors like free-riding. In the case that property rights are not enforceable or other interested parties are not automatically excluded from benefits, the incentives of involved actors can be influenced and consequently the overall output can be reduced for the whole community (Alchian and Demsetz 1973). Due to the fact that the allocation of resources within the entrepreneurial ecosystem directly affects the evaluation of related costs and benefits, renegotiations and underinvestment can jeopardize the inherent value of and productive capital in the ecosystem. Consequently, the organizational artifact "entrepreneurial ecosystem" is comprehensible under the following two conditions. Firstly, a functioning and efficient governance system should ensure that all stakeholders contributing to value creation within the ecosystem receive a return on the collaboratively created value they expected. Secondly, contributing to the ecosystem is only reasonable if the created value within the ecosystem is higher than the sum of all values potentially created by actors without their involvement in the ecosystem, i.e., overall benefits exceed the overall costs within the ecosystem. Conflicting interests and problems arising from incomplete contracts and selfinterests lead to imbalances and can destroy the expected value. How PIs can contribute to solve these problems is discussed in the following section.

4.2 Multiple-principal agent relationships and the costs and benefits of governance mechanisms within an entrepreneurial ecosystem

Generally, the incomplete contract approach focuses on single relationships and single tasks; nevertheless, it also fits to describe corporate governance dilemmas in 
entrepreneurial ecosystems by construing them as a nexus of incomplete contracts (see Zingales 1998). The surrounding of entrepreneurial ecosystems is challenging because of incomplete information about the risks of projects on the one hand and the high requirements concerning the definition and formulation of project goals on the other hand. As publicly funded research projects are naturally complex and multifaceted, the mentioned challenges can potentially endanger the success of the whole project. Additionally, the abovementioned stakeholders have a self-interest and try to influence or control the project. To overcome these problems, PIs can serve as project managers and enforcers of all legitimate interests by reason of their capabilities.

Taking the perspective of the principal-agent theory helps to analyze asymmetric information and consequences in (contractual) relationships between individuals (Jensen and Meckling 1976). From a principalagent perspective, PIs are acting as an agent for all actors within the entrepreneurial ecosystem, what leads to multiple agency roles. This circumstance requires the consideration of multiple governance roles of the PI in the entrepreneurial ecosystem and consequently the existence of different sets of agency costs (Filatotchev et al. 2011). PIs are agents in response of the overall project, assigned and contracted to balance interests and competing claims within the ecosystem. Within their role as an agent, PIs bridge the expectations, thus meet the primary objectives of various actors and constantly signal progress and results to entrepreneurial ecosystem actors, to ultimately contribute to economic and noneconomic value creation processes within entrepreneurial ecosystems.

With regard to information asymmetries, the governance literature distinguishes two different problem categories depending on the status of the contract: "adverse selection"-problems as the result of "hidden characteristics" before the parties reach an arrangement (ex ante), and "moral hazard'-problems which describe "hidden actions" and "hidden information" after contracting (ex post) (Arrow 1984). Both, the principal and the agent, are interested in a reduction of information asymmetries. The agent uses "signaling" to persuade the principal that he/she has the best intentions and his/her statement about his/her characteristics is true, whereas the principal uses "monitoring" to control the agent's actions. Holmström (1979) and others showed that any additional information improves the welfare of the principal and the agent (see Stiglitz 1975; Williamson 1975).
Especially in an entrepreneurial environment where project outcomes are often exposed to high risks, information asymmetries between the principal and the agent undermine the creation of economic and non-economic value within entrepreneurial ecosystems.

To overcome or at least minimize information asymmetries, thus increasing the efficiency of value creation processes, the principal has to evaluate and assess the signals which are sent out by the agent to then decide on whether to enter into bilateral (contractual) relationships or not. In an entrepreneurial ecosystem, for example, the PI acts as an agent for public capital providers such as public research funding agencies. Before a scientist can take on the PI role and is enabled to act as an agent for a public funding agency, a peer evaluation focuses on scientific merits, capabilities to manage the funding project proposed and whether the project has sufficient organization support to be an effective agent for the funding agency. In general, imperfect information about individuals' characteristics can conclude in unbalanced negotiation power and ends up in an incomplete contract and a dissatisfying relationship for both partners (Zingales 1998). Reduced efforts and a suboptimal allocation of resources finally lead to a project outcome that is under its potential value, resulting in a loss of welfare.

In a complex environment as prevalent in entrepreneurial ecosystems, monitoring as well as signaling mechanisms are difficult to establish (Freitas et al. 2013). Signaling and monitoring activities might thereby take various forms. Entrepreneurs could for example use their personal networks and strong ties to business angels to signal their good reputation to get funding (Elitzur and Gavious 2003), and funding agencies could, for example, install a simple monitoring system for the PI such as a quarterly reporting system. However, the PI's task areas are multifaceted. According to Audretsch et al. (2009), the classical private entrepreneur has a dual role: leveraging the existing resources of the business as well as bringing in human capital to the innovation process. Beyond these tasks, the PI as a public sector entrepreneur has to additionally execute many more functions such as supervising and mentoring, managing cultural diversity, or project promotion (Cunningham et al. 2016). The PI as well as the funding agency would agree that managing all involved stakeholders is one of the PI's key responsibilities. But how should the PI credibly report the importance of a research meeting or think tank without any physical output? Especially trust 
building activities between the PI and the other key actors in entrepreneurial ecosystems are necessary to ensure that the PI can use its capabilities to create value.

Besides the possibility to control the agent, the principal can install incentive mechanisms like performancerelated remuneration. It is a fact that the allocation of property rights and the distribution of tasks, also known as the separation of ownership and control, is the origin of all governance dilemmas, but otherwise can be part of the solution. Giving agents ownership shares as part of their remuneration is a common method to align their interests with the interests of the principal-owner. Demsetz (1967) emphasizes that property rights have an incentive as well as a reward component, which both can universally be used in economic settings and are beneficial in contract theory, too. In large-scale publicly funded research projects, property rights matter, but more in terms of intellectual property rights and specific knowledge than in equity stakes. Stephan and Levin (1996: 177) examine reward structures of universitybased scientists and conclude that "basic science is fostered by a mechanism of reputational rights; technological advances - and the products and processes they produce - are fostered by a mechanism of property rights". Individual incentives to engage in the transfer of innovation, i.e., the "privatization" of knowledge, as well as the opportunities of commercialization are based on sufficient intellectual property rights.

\section{PI-centered entrepreneurial ecosystem governance framework}

PIs have to simultaneously maintain relationships with many stakeholders within one single project and all stakeholders have self-interest in realizing value. Trust in the capabilities of the PI as well as between the different actors of the entrepreneurial ecosystems can make controlling and monitoring mechanisms superfluous or can at least lead to a reduction of respective mechanisms. Focusing on strategic tools that keep an overview on the macro level instead of focusing on single actors and relations can help to ensure target achievement and value creation. Using a modified model of the balanced scorecard (Kaplan and Norton 1995) thereby helps the PI to govern the entrepreneurial ecosystem successfully and supports him/her in his/her key role constituting the connective link in publicly funded large-scale research programs.
PIs take an active role in the governance system of an entrepreneurial ecosystem. They are part of their institutional monitoring system as their entrepreneurial contribution to the project is essential for the overall economic and non-economic value creation. Therefore, a detailed discussion about the PI and their relation to other stakeholders in research projects against the background of the principal-agent theory sheds light on common governance dilemmas. As PIs engage with a variety of actors within entrepreneurial ecosystems, they have to navigate different governance mechanisms and deliver a variety of benefits and outcomes such as disruptive knowledge. From a governance perspective, they have to deal with different problem categories resulting from information asymmetries. To be effective and to contribute to efficient governance, PIs need to possess a certain set of primary capabilities that enables them to bridge and overcome prevalent gaps and obstacles between science and business. Drawing this together, we present a PI-centered entrepreneurial ecosystem governance framework that integrates actors that PIs need to deal with, the primary capabilities they need to possess in order to deliver against the principal's primary interests, the problem categories associated with respective bilateral governance relationships as well as related solving mechanisms, to comply with actors' monitoring mechanisms as well as contribute to the economic and non-economic value creation and capture for entrepreneurial ecosystem actors (see Fig. 1).

It is the PI's research excellence and leadership that enable PIs to effectively pursue their scientific mission, coordinate various actors within the scientific field, and deliver publicly funded research programs successfully and on time. The focus of PIs is on scientific value creation and the compliance with respective scientific research objectives. Despite potentially diverging objectives - universities are interested in research income and royalties whereas PIs primarily strive for personal reputation and prestige - it is the PI's research excellence and leadership which facilitate the simultaneous achievement of both targets and the satisfactory resolution of potential conflicts. It is obvious that, due to the iterative and dynamic nature of publicly funded largescale projects, the PI's role as well as the importance and involvement of different entrepreneurial ecosystem actors change over time. In the early stages of project acquisition, PIs act like a principal and decide which research ideas are pursued, how research should technically be organized and the nature of the disruptive 


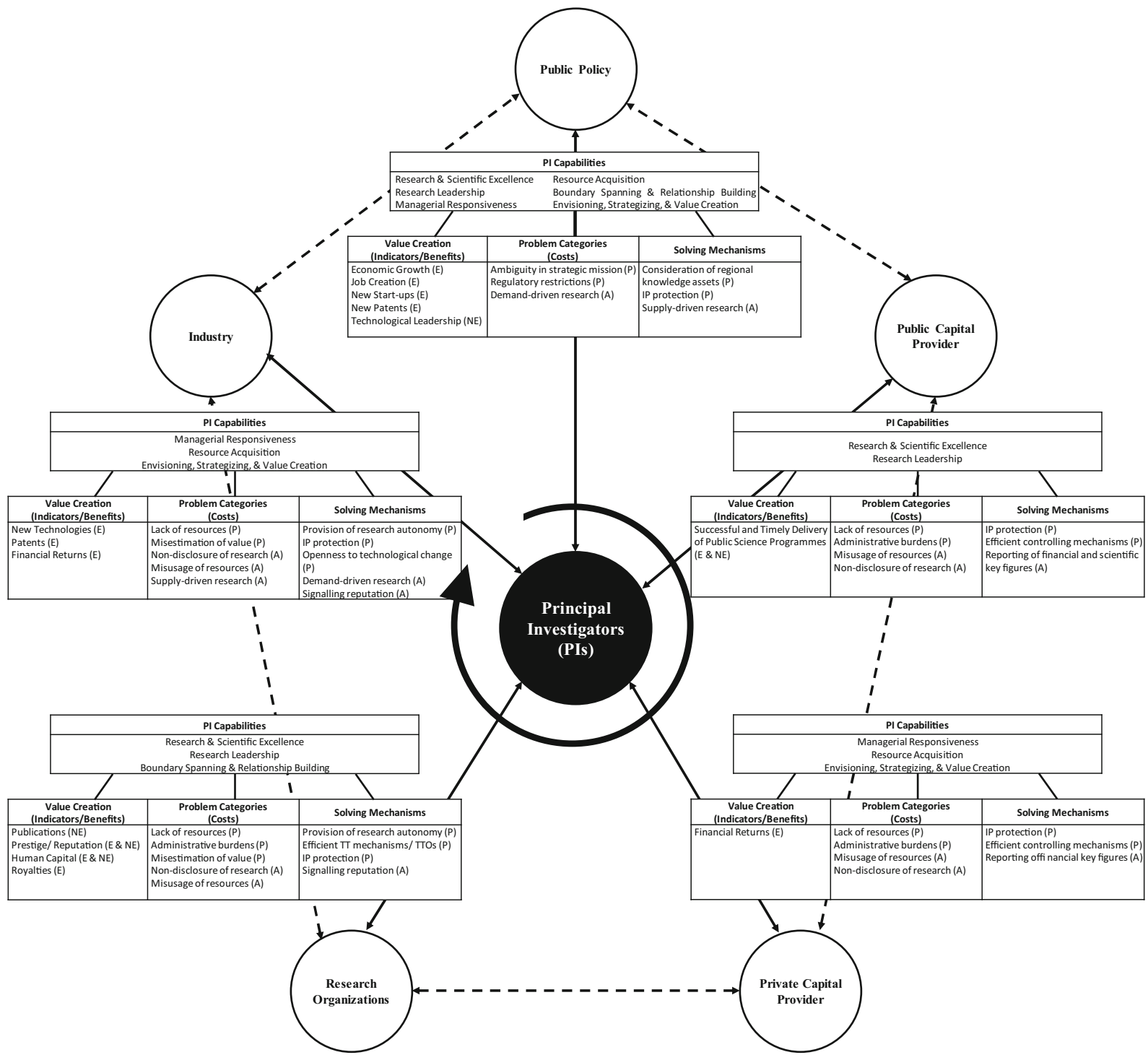

Fig. 1 PI-centered entrepreneurial ecosystem governance framework. Value creation relates to both economic (E) and non-economic (NE) value components $\mid$ Problem categories and solving mechanisms may be principal- $(\mathrm{P})$ or agent-induced (A)

knowledge. In involving other ecosystem actors, they allocate costs and benefits, with some of these costs being covered by the funding received. The PI becomes a resource allocator. When funding of a project is granted, the PI is responsible for the design and implementation of an overall project governance system and as the project progresses they have to monitor the allocation of costs and benefits for each entrepreneurial ecosystem actor. Due to their drive for academic prestige and enhanced reputation, PIs often choose to apply for and engage in very complex multi-stakeholder projects, which are difficult to coordinate. Their boundary spanning and relationship building capabilities enable PIs to successfully deliver on the respective principals' objectives and leverage diverse inputs of various stakeholders efficiently.

As entrepreneurial environment actors, research organizations serve as the natural setting of PIs, provide resources, and control the application, incentives, and rewards. Besides financial outcomes such as royalties and research income, universities are interested in scientific outcomes such as scientific publications as well as human capital development. Additionally, reputation is important for current and future funding by the 
government and other institutions. Due to the fact that the relationship between the PI and the university is long-term orientated, “adverse selection' problems play a tangential role. Rather, moral hazard problems arise from the PI's hidden actions and hidden intensions. Resources can be wasted or distributed in an inefficient way; therefore, there are less benefits potentially occurring to other entrepreneurial ecosystem actors. Furthermore, PIs might have an interest in not disclosing new knowledge and technological breakthroughs, i.e., bypass formal technology transfer systems (Menter 2016). In order to prevent respective activities, universities need to provide institutional resources that PIs require and reduce the administrative burdens associated with the disclosure of innovations. The university might additionally establish monitoring mechanisms to control the PI over at least three main dimensions: First, financial reporting to ensure an optimal allocation of resources. Second, Technology Transfer Offices (TTOs) offer IP protection and efficient technology transfer mechanisms to facilitate the commercialization of knowledge. PIs are required to adhere to formal technology transfer policies and procedures. Third, Ethics Committees supervise ethical standards and make sure that PIs comply with the norms and values of the university as well as their professional scientific communities. TTOs only have limited control over the PI, which in turn can result in suboptimal allocations of resources and an overall loss in welfare. Despite institutionalized monitoring and control systems, universities need to provide PIs adequate research autonomy and balance this against appropriate IP protection systems in order to increase efficient value creation processes that capture the benefits for relevant entrepreneurial ecosystem actors. PIs need to invest in building their reputation to signal their capabilities.

The industry actor in the entrepreneurial ecosystem is becoming an increasingly important collaborator for PIs, especially SMEs. These entrepreneurial ecosystem actors are one of the main recipients of disruptive knowledge that can have direct benefit on their firm. Together with public and private capital providers such as public research funding agencies or venture capitalists, industry mainly contributes financial support to the research project. Reversely, the implication is that all financiers focus on financial controls. Moreover, industry partners can contribute other physical factors like equipment, labor, and production or testing space. In return, they expect new disruptive knowledge and the access to expertise or as described by Stam (2015) "productive entrepreneurship." SMEs engage in publicly funded programs to absorb new knowledge and get access to expertise, as they do not have the internal resources or capacity. For all industry actors, the main monitoring mechanism is financial and this may not be of a sufficient scale to engage the interest of PIs. By their resource acquisition skills and their managerial responsiveness, PIs deal with imposed managerial tensions and thus enable efficient value creation processes within the respective research projects, based on their envisioning, strategizing, and value creation capabilities. Openness to technology change constitutes a prerequisite for respective collaborations as economic and noneconomic value can only be created by the application of new knowledge. The imperfect contract nature of publicly funded programs can facilitate this openness. A lack of sufficient resources might result in suboptimal value creation processes, some entrepreneurial ecosystem actors bearing more of the costs. To ensure the adequate disclosure of new disruptive knowledge, the distribution of intellectual property rights has to be agreed before the actual project start, i.e., ex ante. As public-private partnerships are primarily based on collaborative research, firms still have to ensure some research autonomy for the PI. In this context, the reputation of PIs serves as a good signal to sustain the autonomy that they require to advance their research efforts and to act as an entrepreneurial actor.

Private capital providers are solely interested in financial returns, the main benefit, whereas public funding agencies focus on scientific reporting as well as a research governance reported by the PI and the value for money. Both types of capital providers have to avoid two governance dilemmas related to the PI: firstly, "adverse selection"-problems in the early stage could lead to the funding of suboptimal projects or optimal projects with suboptimal leadership. Secondly, "moral hazard"-behavior by the PI jeopardizes the expected rewards and benefits. Especially the timely delivery of publicly funded programs is important for the funding agency. Thus, capital providers consistently require updates of reports, providing them insights into the current project status, completed milestones, upcoming activities, and actual and projected benefits. Although reports need to be information-dense, they must not constitute administrative burdens that add additional costs to entrepreneurial ecosystem actors. This can actually constrain the PI to engage in value creating 
activities, i.e., conducting research, allocating resources, boundary spanning activities, etc.

The government, thus public policy, expects multiple benefits and rewards. Policymakers focus on economic impacts like new start-ups and job creation, economic stimuli sent by licensed new knowledge and technologies as well as the implementation of science and SME policies in general. These targets are abstract at the beginning of funded projects and therefore; moral hazard could dominate the relation between the PI and the policymaker. Public policies set the basis for sufficient intellectual property protection mechanisms, thus are critical drivers in establishing optimal governance systems. As government development agencies are interested in scientific breakthroughs, PIs should be encouraged to conduct collaborative research, enabling PIs to think outside the box, i.e., pool different knowledge sources to open up and reach new technological frontiers. This potentially expands the boundaries of existing entrepreneurial ecosystems as well as delivering disruptive knowledge.

Combining all actors in entrepreneurial ecosystems and taking their multiple objectives and expected rewards into account, the PI as a key player can reduce complexity by navigating through the funded research project to deliver the envisaged benefits. As scientists in the PI role, they bring together different entrepreneurial ecosystem actors and are typically the first contact person for research organizations, industry, capital providers, and policy. Since the importance of various actors as well as the significance of respective collaborations changes over time, the interaction with PIs is iterative and dynamic, hence not linear (as indicated by the bold arrow in Fig. 1). Whereas the interaction with e.g. capital providers is rather intense in the project initiation phase, the PI subsequently mainly engages with industry to create economic and non-economic value, but still has to report to capital providers also in the ongoing phases until project completion.

All entrepreneurial ecosystem actors monitor and control the PIs' activities, but their mechanisms are ambiguous: control instruments and reports should be used as a means to an end and not an end in itself to minimize costs. Besides the discussed monitoring opportunities, PIs use signaling to convince other entrepreneurial ecosystem actors that they have the best intention to reach all targets, e.g., disclose new technologies and ideas, commercialize knowledge within the agreed framework, etc. Signals are the results of the agent's previous actions and are only valuable if they are visible and verifiable. Successfully completed projects, patent applications, or scientific publications are suitable signals for certain actors, whereby it should be noted that all these measurable outputs are reducible to the PI's capabilities. PIs need to have capabilities that enable them to operate, engage, and mobilize the necessary resources and support to fulfill publicly funded project commitments, realize their own scientific ambitions, and in doing so, create influence over their own research space while adhering to different governance mechanisms. Information asymmetries have to be reduced to enable efficient value creation processes. Both the principal as well as the agent of every bilateral governance relationship within entrepreneurial ecosystems have to engage in removing obstacles to value creation, as respective objectives can only be reached by jointly addressing prevalent problem categories.

\section{Conclusion and future research avenues}

The purpose and contribution of our paper is to present a micro level PI-centered governance framework, which is in contrast to the macro level frameworks posited in the literature. In presenting our framework, we also address some of the criticisms of entrepreneurial ecosystems and in doing so identify the value creation (benefits), PI capabilities, the problem categories (costs), and solving mechanisms that PIs can use to govern effectively and efficiently large-scale publicly funded research programs. Our paper has highlighted the influential role that scientists play in the PI role in contributing to the development and growth of entrepreneurial ecosystems and the multitude of actors. Our framework highlights the governance mechanisms; PIs have to navigate effectively to deliver publicly funded research programs based on imperfect contracts within entrepreneurial ecosystems that allocate costs and benefits to relevant entrepreneurial ecosystem actors. Our framework addresses some of the criticisms of entrepreneurial ecosystems research to date and makes the following contributions.

First, our micro level approach from a PI perspective is a modest attempt to develop an operational level understanding of entrepreneurial ecosystem as highlighted by Stam and Bosma (2015). We do this by focusing on the PI capabilities, value creation (benefits), the problem categories (costs), and solving mechanisms 
relevant for each entrepreneurial ecosystem actor from an individual perspective - that of the PI. Second, Stam and Spigel (2015) suggest that there is no clarity about cause and effect in relation to specific factors and the units of analysis and attribution of contributory factors for economic outcomes. Our micro level PI-centered governance framework attempts to address this by mapping out the cause and effect by suggesting different value creation indicators for each entrepreneurial ecosystem actor relevant to the PI as well as the problem categories and solving mechanisms that PIs experience and use in the governance of large-scale publicly funded research. PIs mobilize different entrepreneurial ecosystem actors to create new projects, and in doing so, arbitrate and allocate costs and benefits. Future studies might thus operationalize our framework. Our third contribution lies around existing studies using different network definitions, being place-/cluster-based and conceptualizing frameworks that are static and do not account for the evolution over time (see Alvedalen and Boschma 2017). Our proposed framework overcomes the network definitional problem by taking the unit of analysis at the individual level and focusing on one of the influential actors that generates disruptive knowledge - one of the core elements of an entrepreneurial ecosystem. Moreover, focusing on the PI means that our proposed model is not place-/cluster-based, considering the time-based, dynamic, and iterative aspects of publicly funded large-scale projects.

Future studies can use cross-country programs such as Horizon 2020, European Research Council PI grant holders as well as national funded PIs as their unit of analysis. The focus at the PI and project level can be used to examine the evolution of entrepreneurial ecosystem through the prism of large-scale publicly funded research. The very nature of publicly funded programs means they are not static but rather dynamic as they evolve over time. Our conceptual model overcomes the static nature of entrepreneurial ecosystem frameworks as our proposed framework allows for time evolution and the weighting of entrepreneurial ecosystem actors' importance during the different project phases.

For the economic advancement and the contribution to the productive capital of an entrepreneurial ecosystem, PIs need to possess capabilities to lead, manage, reconcile, and govern scientific targets with benefits such as economic and non-economic value creation. Through their boundary spanning activities and their ability to envision and strategize, PIs leverage actors and resources to create disruptive knowledge and enable other entrepreneurial ecosystem actors to capture value. The underlying governance dilemma at a micro level of entrepreneurial ecosystems is that different stakeholders, i.e., principals such as research organizations or capital providers, are competing if not attempting to assert primary control over the agent, i.e., the PI as the supplier of disruptive knowledge. PIs consequently have to deal with different forms of control mechanisms and become proficient in navigating, arbitrating, and managing these control mechanisms in order to create and generate benefits and value for all relevant entrepreneurial ecosystem actors at a project level. Moreover, PIs have to create their own governance systems at the project level as well as navigate institutional governance systems to fulfill their scientific mission and add economic and non-economic value to relevant entrepreneurial ecosystems.

How PIs navigate the different governance mechanisms matters and can constrain the benefits and value creation for entrepreneurial ecosystem actors. Moreover, how PIs efficiently and effectively deliver on publicly funded large-scale multi-stakeholder projects matters particularly as they are agents for funding agencies and other government agents in supporting and developing SME competitiveness. SMEs have limited influence over universities in comparison to larger firms so engaging with PIs using public funding is necessary for them to access disruptive knowledge, human capital, and expertise.

Finally, this paper emphasized the importance of taking a PI-centered approach in viewing entrepreneurial ecosystems, given the influential role and foundational importance of PIs to the vibrancy and sustainability of entrepreneurial ecosystems. Our PI-centered approach opens up several fruitful avenues of future research in at least three distinct research fields: the PI literature, the entrepreneurial ecosystem literature as well as the governance literature.

From a PI literature perspective, there is a need to conduct empirical research on how PIs actually arbitrate, navigate, shape, and circumvent the complex governance systems they engage in at a micro perspective as presented in our Fig. 1. Future studies should consider the potential differences across universities, funding agencies, and institutional settings and should investigate how PIs deploy their capabilities to achieve the desired benefits for entrepreneurial ecosystem actors. Moreover, research on what signals PIs actually send 
as an agent to different actors in a principal position that afford them more autonomy and at what stage this signaling becomes effective with multiple principals is needed. Empirical studies are warranted on how PIs understand and deal with moral hazard and adverse selection problem categories and how this varies across disciplines and types of institutional settings. Addressing these research themes will further advance the entrepreneurial ecosystem research, particularly from the individual perspective as identified and advocated by Stam (2015).

From an entrepreneurial ecosystem literature perspective, it is critical to investigate the influence of the competitive positing of an entrepreneurial ecosystem actor on the role as a principal. Moreover, the active or passive role of an ecosystem actor might influence its tendency to shape and control agents such as PIs. The role of public policy-shaping entrepreneurial behavior and thus relationships within entrepreneurial ecosystems is another very fruitful area of future research. Finally, with the growth influence of virtual ecosystems, principal-agent roles should be analyzed more in depth.

From a governance literature perspective, insights from classical agency research addressing relationships between managers and owners of firms should be analyzed and transferred toward bilateral governance relationships in entrepreneurial ecosystems. Especially bilateral contracts and their mechanisms to avoid "adverse selection" and overcome "moral hazard" behavior of agents should be the focus of future research, taking the important role of PIs into consideration. Incentive as well as control structures that are established in private sector organizations have at least potential to be helpful in the public sector, too. Empirical investigations on how the actors in entrepreneurial ecosystems actually deal with the identified problem categories and which mechanisms are beneficial to increase economic and noneconomic value creation would thereby enrich the governance literature. Efficient signaling and reporting structures could avoid agency costs and the resulting welfare loss and consequently help to create a more valuable and transparent entrepreneurial ecosystem.

Taking a PI-centered approach to future studies of entrepreneurial ecosystem is essential as PIs are agents for entrepreneurial ecosystem actors and their effectiveness matters to contributing to the functioning, vibrancy, development, and growth of entrepreneurial ecosystems. This paper outlines a governance framework that integrates distinct research fields associated with economic and non-economic value creation processes in entrepreneurial ecosystems to improve bilateral governance relationships that aims at motivating other researchers to focus their attention on public sector actors such as PIs.

Acknowledgements The authors wish to acknowledge the Special Issue Editors and reviewers for their constructive feedback which has shaped this paper. James A. Cunningham acknowledges the funding support of Science Foundation Ireland (SFI) and cofunding under the European Regional Development Fund under Grant No. 13/RC/2073.

Open Access This article is distributed under the terms of the Creative Commons Attribution 4.0 International License (http:// creativecommons.org/licenses/by/4.0/), which permits unrestricted use, distribution, and reproduction in any medium, provided you give appropriate credit to the original author(s) and the source, provide a link to the Creative Commons license, and indicate if changes were made.

\section{References}

Acs, Z. J., Audretsch, D. B., Lehmann, E. E., \& Licht, G. (2017). National systems of innovation. The Journal of Technology Transfer, 42, 997-1008.

Acs, Z. J., Autio, E., \& Szerb, L. (2014). National systems of entrepreneurship: measurement issues and policy implications. Research Policy, 43(3), 476-494.

Acs, Z. J., Braunerhjelm, P., Audretsch, D. B., \& Carlsson, B. (2009). The knowledge spillover theory of entrepreneurship. Small Business Economics, 32(1), 15-30.

Adler, N., Elmquist, M., \& Norrgren, F. (2009). The challenge of managing boundary-spanning research activities: experiences from the Swedish context. Research Policy, 38(7), 1136-1149.

Alchian, A. A., \& Demsetz, H. (1973). The property right paradigm. The Journal of Economic History, 33(1), 16-27.

Alvedalen, J., \& Boschma, R. (2017). A critical review of entrepreneurial ecosystems research: towards a future research agenda. European Planning Studies, 25(6), 887-903.

Arrow, K. J. (1984). The Economics of Agency: DTIC Document.

Audretsch, D. B., \& Belitski, M. (2016). Entrepreneurial ecosystems in cities: establishing the framework conditions. The Journal of Technology Transfer, 1-22.

Audretsch, D. B., \& Stephan, P. E. (1996). Company-scientist locational links: the case of biotechnology. The American Economic Review, 86(3), 641-652.

Audretsch, D. B., Lehmann, E. E., \& Plummer, L. A. (2009). Agency and governance in strategic entrepreneurship. Entrepreneurship Theory and Practice, 33(1), 149-166.

Auerswald, P. E. (2015). Enabling entrepreneurial ecosystems: insights from ecology to inform effective entrepreneurship policy.

Baglieri, D., \& Lorenzoni, G. (2014). Closing the distance between academia and market: experimentation and user 
entrepreneurial processes. The Journal of Technology Transfer, 39(1).

Boardman, C., \& Ponomariov, B. (2014). Management knowledge and the organization of team science in university research centers. The Journal of Technology Transfer, 39(1), $75-92$.

Boehm, D., \& Hogan, T. (2014). 'A jack of all trades': the role of PIs in the establishment and management of collaborative networks in scientific knowledge commercialisation. The Journal of Technology Transfer, 39(1), 134-149.

Casati, A., \& Genet, C. (2014). Principal investigators as scientific entrepreneurs. The Journal of Technology Transfer, 39(1), $11-32$.

Coase, R. H. (1937). The nature of the firm. Economica, 4(16), 386-405.

Cohen, B. (2006). Sustainable valley entrepreneurial ecosystems. Business Strategy and the Environment, 15(1), 1-14.

Colombo, M. G., Doganova, L., Piva, E., D’Adda, D., \& Mustar, P. (2015). Hybrid alliances and radical innovation: the performance implications of integrating exploration and exploitation. The Journal of Technology Transfer, 40(4), 696-722.

Cunningham, J., O'Reilly, P., O'Kane, C., \& Mangematin, V. (2014). The inhibiting factors that principal investigators experience in leading publicly funded research. The Journal of Technology Transfer, 39(1), 93-110.

Cunningham, J. A., O'Reilly, P., O'Kane, C., \& Mangematin, V. (2015a). Managerial challenges of publicly funded principal investigators. International Journal of Technology Management, 68(3-4), 176-202.

Cunningham, J. A., Mangematin, V., O'Kane, C., \& O'Reilly, P. (2015b). At the frontiers of scientific advancement: the factors that influence scientists to become or choose to become publicly funded principal investigators. The Journal of Technology Transfer, 1-20.

Cunningham, J. A., O’Reilly, P., O’Kane, C., \& Mangematin, V. (2016). Publicly funded principal investigators as transformative agents of public sector entrepreneurship. Essays in Public Sector Entrepreneurship (pp. 67-94). Springer.

Demsetz, H. (1967). Toward a theory of property rights. American Economic Review, 57, 347-359.

Del Giudice, M., Nicotra, M., Romano, M., \& Schillaci, C. E. (2016). Entrepreneurial performance of principal investigators and company culture: relation and influences. Journal of Technology Transfer. https://doi.org/10.1007/s10961-0169499-y.

Elitzur, R., \& Gavious, A. (2003). Contracting, signaling, and moral hazard: a model of entrepreneurs, 'angels,' and venture capitalists. Journal of Business Venturing, 18(6), 709-725.

Etzkowitz, H. (1983). Entrepreneurial scientists and entrepreneurial universities in American academic science. Minerva, 21, 198-233.

Etzkowitz, H. (2003). Research groups as 'quasi-firms': the invention of the entrepreneurial university. Research Policy, 32(1), 109-121.

Feeney, M., \& Welch, E. (2014). Academic outcomes among principal investigators, co-principal investigators, and nonPI researchers. The Journal of Technology Transfer, 39(1), $111-133$

Filatotchev, I., Zhang, X., \& Piesse, J. (2011). Multiple agency perspective, family control, and private information abuse in an emerging economy. Asia Pacific Journal of Management, 28(1), 69-93.

Forti, E., Franzoni, C., \& Sobrero, M. (2013). Bridges or isolates? Investigating the social networks of academic inventors. Research Policy, 42(8), 1378-1388.

Freeman, C. (1987). Technical innovation, diffusion, and long cycles of economic development. In The long-wave debate (pp. 295-309). Berlin, Heidelberg: Springer.

Freitas, I. M. B., Geuna, A., \& Rossi, F. (2013). Finding the right partners: institutional and personal modes of governance of university-industry interactions. Research Policy, 42(1), 5062.

Gittelman, M., \& Kogut, B. (2003). Does good science lead to valuable knowledge? Biotechnology firms and the evolutionary logic of citation patterns. Management Science, 49(4), 366-382.

Guerrero, M., Cunningham, J. A., \& Urbano, D. (2015). Economic impact of entrepreneurial universities' activities: an exploratory study of the United Kingdom. Research Policy, 44(3), 748-764.

Hagendijk, R., \& Irwin, A. (2006). Public deliberation and governance: engaging with science and technology in contemporary Europe. Minerva, 44(2), 167-184.

Holmström, B. (1979). Moral hazard and observability. The Bell Journal of Economics, 10(1), 74-91.

Isenberg, D. (2011). The entrepreneurship ecosystem strategy as a new paradigm for economic policy: principles for cultivating entrepreneurship. Presentation at the Institute of International and European Affairs.

Jain, S., George, G., \& Maltarich, M. (2009). Academics or entrepreneurs? Investigating role identity modification of university scientists involved in commercialization activity. Research Policy, 38(6), 922-935.

Jensen, M. C., \& Meckling, W. H. (1976). Theory of the firm: managerial behavior, agency costs and ownership structure. Journal of Financial Economics, 3(4), 305-360.

Kaplan, R. S., \& Norton, D. P. (1995). Putting the balanced scorecard to work. Performance measurement, management, and appraisal sourcebook, 66, 17511.

Kidwell, D. K. (2013). Principal investigators as knowledge brokers: a multiple case study of the creative actions of PIs in entrepreneurial science. Technological Forecasting and Social Change, 80(2), 212-220.

Kidwell, D. K. (2014). Navigating the role of the principal investigator: a comparison of four cases. The Journal of Technology Transfer, 39(1), 33-51.

Krugman, P. R. (1991). Geography and trade. MIT press.

Kshetri, N. (2014). Developing successful entrepreneurial ecosystems: lessons from a comparison of an Asian tiger and a Baltic tiger. Baltic Journal of Management, 9(3), 330-356.

Kuratko, D. F., \& Menter, M. (2017). The role of public policy in fostering technology based nascent entrepreneurship. In J. A. Cunningham \& C. O'Kane (Eds.), Technology based nascent entrepreneurship: implications for economic policymaking (pp. 19-52). Basingstoke: Palgrave Macmillan.

Lam, A. (2010). From 'ivory tower traditionalists' to 'entrepreneurial scientists'? Academic scientists in fuzzy university industry boundaries. Social Studies of Science, 40, 307-340.

Lehmann, E. E., \& Menter, M. (2016). University-industry collaboration and regional wealth. The Journal of Technology Transfer, 41(6), 1284-1307. 
Leyden, D. P., \& Menter, M. (2017). The legacy and promise of Vannevar Bush: rethinking the model of innovation and the role of public policy. Economics of Innovation and New Technology, 1-18, forthcoming. doi:https://doi. org/10.1080/10438599.2017.1329189.

Lundvall, B. Å. (2010). National systems of innovation: toward a theory of innovation and interactive learning (Vol. 2). Anthem Press.

Mack, E., \& Mayer, H. (2016). The evolutionary dynamics of entrepreneurial ecosystems. Urban Studies, 53(10), 21182133.

Malecki, E. J. (2011). Connecting local entrepreneurial ecosystems to global innovation networks: open innovation, double networks and knowledge integration. International Journal of Entrepreneurship and Innovation Management, 14(1), 3659.

Mangematin, V., O'Reilly, P., \& Cunningham, J. (2014). PIs as boundary spanners, science and market shapers. The Journal of Technology Transfer, 39(1), 1-10.

Markusen, A. (1996). Sticky places in slippery space: a typology of industrial districts. Economic Geography, 72(3), 293-313.

Mason, C., \& Brown, R. (2014). Entrepreneurial ecosystems and growth oriented entrepreneurship. Final Report to OECD, Paris, 30(1), 77-102.

McAdam, R., Miller, K., McAdam, M., \& Teague, S. (2012). The development of university technology transfer stakeholder relationships at a regional level: lessons for the future. Technovation, 32(1), 57-67.

Menter, M. (2016). Principal investigators and the commercialization of knowledge. In D. B. Audretsch, E. E. Lehmann, S. Vismara, \& M. Meoli (Eds.), University evolution, entrepreneurial activity and regional competitiveness (pp. 193-203). Heidelberg: Springer.

Murray, F. (2004). The role of academic inventors in entrepreneurial firms: sharing the laboratory life. Research Policy, 33(4), 643-659.

Nambisan, S., \& Baron, R. A. (2013). Entrepreneurship in innovation ecosystems: entrepreneurs' self-regulatory processes and their implications for new venture success. Entrepreneurship Theory and Practice, 37(5), 1071-1097.

O'Kane, C. (2016). Technology transfer executives' backwards integration: an examination of interactions between university technology transfer executives and principal investigators. Technovation. https://doi. org/10.1016/j.technovation.2016.08.001.

O'Kane, C., Cunningham, J., O'Reilly, P., \& Mangematin, V. (2015). Underpinning strategic behaviours and posture of principal investigators in transition/uncertain environments. Long Range Planning, 43(3), 200-214.

Organ, D., \& Cunningham, J. (2014). Role frame dynamics and the proliferation of entrepreneurial propensity in the university context, paper presented at the Technology Transfer Society Conference, John Hopkins University, Baltimore, 23-24 October.
Pitelis, C. (2012). Clusters, entrepreneurial ecosystem co-creation, and appropriability: a conceptual framework. Industrial and Corporate Change, 21(6), 1359-1388.

Porter, M. E. (1998). Clusters and the new economics of competition (Vol. 76, No. 6, pp. 77-90). Boston: Harvard Business Review.

Slaughter, S., \& Leslie, L. L., (1997). Academic capitalism: politics, policies and the entrepreneurial university. The Johns Hopkins University Press, Baltimore, MA. Transfer Society Conference, John Hopkins University, Baltimore, 23-24 October.

Sölvell, Ö. (2015). Construction of the cluster commons. In D. B. Audretsch, A. Link, \& M. Walshok (Eds.), The Oxford handbook of local competitiveness (pp. 84-101). New York: Oxford University Press.

Spigel, B. (2015). The relational organization of entrepreneurial ecosystems. Entrepreneurship Theory and Practice. https://doi.org/10.1111/etap.12167.

Stam, E. (2015). Entrepreneurial ecosystems and regional policy: a sympathetic critique. European Planning Studies, 23(9), 1759-1769.

Stam, E., \& Bosma, N. (2015). Local policies for high-growth firms. Oxford Handbook of Local Competitiveness, 286-305.

Stam, E., \& Spigel, B. (2016). Entrepreneurial ecosystems and regional policy. In R. Blackburn, D. De Clercq, J. Heinonen, \& Z. Wang (Eds.), Sage handbook for entrepreneurship and small business. London: SAGE.

Stangler, D., \& Bell-Masterson, J. (2015). Measuring an entrepreneurial ecosystem. Kauffman Foundation Research Series on City, Metro, and Regional Entrepreneurship, pp. 1-16.

Stephan, P. E., \& Levin, S. G. (1996). Property rights and entrepreneurship in science. Small Business Economics, 8(3), 177-188.

Stiglitz, J. E. (1975). Incentives, risk, and information: notes towards a theory of hierarchy. The Bell Journal of Economics, 6(2), 552-579.

Suresh, J., \& Ramraj, R. (2012). Entrepreneurial ecosystem: case study on the influence of environmental factors on entrepreneurial success. European Journal of Business and Management, 4(16), 95-102.

Szerb, L., Acs, Z. J., Ortega-Argilés, R., \& Komlosi, E. (2015). The entrepreneurial ecosystem: the regional entrepreneurship and development index. Available at SSRN 2642514.

Williamson, O. E. (1975). Markets and hierarchies, analysis and antitrust implications. New York: Simon \& Schuster.

Williamson, O. E. (1985). The economic intstitutions of capitalism. Simon and Schuster.

Williamson, O. E. (1989). Transaction cost economics. Handbook of industrial organization, 1, 135-182.

Zingales, L. (1998). Corporate governance. In The New Palgrave Dictionary of Economics (pp. 1-20). Basingstoke: Palgrave Macmillan.

Zucker, L. G., Darby, M. R., \& Armstrong, J. S. (2002). Commercializing knowledge: University science, knowledge capture, and firm performance in biotechnology. Management Science, 48(1), 138-153. 